\title{
A vida segundo o Cristo compassivo e misericordioso
}

\author{
Life according to the compassionate and merciful Christ
}

\author{
Waldecir Gonzaga * \\ Doaldo Ferreira Belem**
}

\footnotetext{
* Doutor em Teologia Bíblica (Pontifícia Universidade Gregoriana, Roma), Mestre em Teologia Bíblica (Pontifícia Universidade Gregoriana, Roma).

Diretor e Professor de Teologia Bíblica do Departamento de Teologia da Pontifícia Universidade Católica do Rio de Janeiro, Brasil. waldecir@puc-rio.br

* * Doutorando em Teologia (Pontifícia Universidade Católica do Rio de Janeiro), Mestre em Teologia (Pontifícia Universidade Católica do Rio de Janeiro). doaldofb@uol.com.br
}

Recebido em: 29/06/2020 Aprovado em: 15/04/2021

Licença Creative Commons CC BY 4.0 (c) (i)

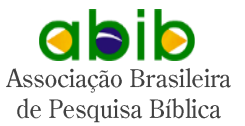

\section{Resumo}

O tema que nos é proposto para esta edição de Estudos Bíblicos "Cuidar da vida" constitui um desafio para todos nós, sobremaneira diante de toda a situação criada no mundo frente à atual pandemia do Coronavírus (COVID-19) e todos os demais sofrimentos, dificuldade e problemas que enfrentamos diariamente, como a ausência de paz no mundo, as migrações forçadas que estamos presenciando na atualidade, a fome, a miséria, racismo, intolerância, falta de políticas públicas, saúde e educação, as perseguições a cristãos in odium fidei e a violência crescentes em nosso meio. $\mathrm{O}$ debruçar-nos sobre o Cristo compassivo e misericordioso nos conduz dentro daquilo que se encontra no coração do Deus da vida, realçado ainda mais no mistério e ministério do Verbum Incarnatus: "Eu vim para que todos tenham vida e a tenham em abundância” (Jo 10,10). O Novo Testamente nos apresenta modos expressivos de cuidar da vida, como a via caritatis, o amor ao próximo, o cuidado com os mais fragilizados, a prática da misericórdia, os rituais de pureza e todas as demais formas de defender a saúde e a vida. Relendo os textos do Novo Testamento, deparamo-nos com um dado: enquanto os sinóticos e cartas paulinas trabalham o tema da misericórdia (compaixão) como defesa da vida, em todos os sentidos, a literatura joanina não emprega este termo e sim "vida". Nosso artigo quer colaborar oferecendo um estudo nessa dupla direção e forma de cuidar da vida.

Palavras-chave: Cristo. Misericórdia. Vida. Corpora.

\begin{abstract}
The theme proposed to us for this edition of Biblical Studies "Caring for life" is a challenge for all of us, greatly in view of the whole situation created in the world in the face of the current Coronavirus pandemic (COVID-19) and all the other sufferings, difficulty and problems we face daily, such as the absence of peace in the world, the forced migrations we are currently witnessing, hunger, misery, racism, intolerance, lack of public policies, health and education, persecution of Christians in odium fidei and increasing violence in our midst. Looking at the compassionate and merciful Christ leads us into what is in the heart of the God of life, further emphasized in the mystery and ministry of the Verbum Incarnatus: "I have come that all may have life and have it abundantly" (John 10,10).
\end{abstract}


The New Testament presents us expressive ways of caring for life, such as the via caritatis, the love of others, the care of the most fragile, the practice of mercy, the rituals of purity and all other ways of defending health and life. Rereading the texts of the New Testament, we come across one fact: while the synoptics and Pauline letters work on the theme of mercy (compassion) as a defense of life, in every way, Johannine literature does not employ this term but rather "life". Our article wants to collaborate by offering a study in this dual direction and way of taking care of life.

Keywords: Christ. Mercy. Life. Corpora.

\section{Introdução}

A vida é o tema que perpassa todas as Sagradas Escrituras, Antigo Testamento e Novo Testamento, desde o livro do Gênesis até o livro do Apocalipse. Há várias formas de se cuidar da vida. O grande modelo de cuidado é o do próprio Criador, que tudo criou e colocou nas mãos dos seres humanos, para que cuidassem da Casa Comum, não se restringindo apenas aos humanos (Gn 1-2), como tem nos alertado o Papa Francisco, na Laudato Si' (2015). Tendo presente as muitas formas de se cuidar da vida, neste artigo, queremos ressaltar que uma delas, e de superlativa importância, é aquela revelada pelos atos de bondade do Cristo compassivo e misericordioso (GONZAGA, 2016). O Novo Testamento traz, e de forma abundante, o termo misericórdia, na dimensão do éleos de Deus (BULTMANN, 1967), também traduzido por compaixão, seja pelos atos de Cristo, seja pelos ensinamentos e testemunhos dos Apóstolos. Porém, João se difere do resto do Novo Testamento. João não traz o termo misericórdia e sim vida. Estas duas formas, ainda que terminologicamente diferentes, de cuidar dos mais fragilizados, complementam-se e têm muito a nos dizer. É isto que queremos fazer neste artigo, o qual fará uma abordagem sobre esta forma diversa e complementar de cuidar da vida, que encontramos presente nos vários corpora do Novo Testamento, que é nosso campo de pesquisa, seja nos Evangelhos seja nas Cartas.

Sendo manifestada também pelos atos de misericórdia, a vida é um dom a ser defendido e cuidado com amor (BUCHSEL, 1966), seja na dimensão hebraica, no AT, do hesed de Deus (ZOBEL, 2003) e do rahămîm de Deus (SIMIAN-YOFRE, 2008), seja na dimensão grega do agapé de Cristo e dos irmãos, no NT. O amor defende e promove a vida ( $\mathrm{Jd} 21)$, que pode ser definida tanto na dimensão da vida natural $(z \bar{o} \bar{e})$ como no modo e estilo de vida (bios), com toda a sua força ética. Tendo presente a realidade do amor que gera e defende a vida, é que queremos analisar também a forma joanina de expressar o cuidado com a vida. Enquanto os Sinóticos abundam o termo "misericórdia" como forma de cuidar da vida, João esbanja o termo "vida", deixando claro que Cristo veio "a fim de que tenham vida e a tenham em abundância" (Jo 10,10). Neste sentido, a literatura joanina não emprega a terminologia, mas é possível se chegar ao mesmo conteúdo por analogia, visto que o agir do Cristo, o bom pastor, é e será sempre misericordioso, e o agir do pai compassivo para com o filho pródigo (Lc 15,1132), com misericórdia, apenas para recordar um exemplo, é e será sempre para promover a vida. 


\section{Misericórdia no Novo Testamento}

O termo misericórdia está presente, de forma ampla e abundante, desde o AT (o hesed de Deus) (ZOBEL, 2003) até o NT (o éleos de Deus) (BULTMANN, 1967). Ele também foi profundamente assumido pelos Padres da Igreja, a exemplo da Policarpo em sua 2Filipenses 1,1 (POLICARPO DE ESMIRNA, 1950) e nos Documentos antigos e atuais da Igreja, que sempre se preocupou em ser canal da misericordia Dei para os homens e mulheres ao longo da história da salvação ${ }^{1}$. Em relação aos últimos, por exemplo, podemos mencionar a Carta Encíclica Dives in Misericordia (JOÃO PAULO II, 1980), que discorreu sobre "Deus que é rico em misericórdia"; a Carta Motu Proprio Misericordia Dei (JOÃO PAULO II, 2002), que tratou do tema da "Misericórdia de Deus que reconcilia seus filhos e lhes abre o caminho da salvação a partir do sacramento da Penitência"; até chegarmos à recente Bula de Proclamação do Jubileu Extraordinário do Ano da Misericórdia Misericordiae Vultus, que nos reafirma que "Jesus Cristo é o rosto da misericórdia do Pai e que nos convida a sermos misericordiosos como o Pai é misericordioso" (FRANCISCO, 2015). Aqui vale a pena recordar o grande convite que o Papa Francisco nos fez em sua Exortação Apostólica Pós Sinodal Evangelii Gaudium (2013) para que cuidemos e defendamos sobremaneira dos mais fragilizados, como práticas de bondade e misericórdia. Portanto, o tema misericórdia, como cuidado compassivo e bondoso do Senhor, conduz-nos diretamente ao coração do NT, que aqui pretendemos enfocar a partir de seus diversos corpora (Sinopticum, Joannicum, Paulinum e Catholicum).

Em primeiro lugar, é interessante ver uso dos termos no grego do NT para falar da presença ou ausência da misericórdia neste corpus biblicum: os termos mais comuns são eleéo e éleos (BULTMANN, 1967), usados para indicar a atitude que Deus quer de cada um de nós, seus filhos e filhas, indicando a linha da bondade, como o proceder comum nos relacionamentos mútuos, a exemplo do que temos em Mt 23,23, ou ainda no gesto de "mostrar misericórdia/compaixão", como em Lc 10,37, nas ações do Bom Samaritano. A Septuaginta usa o termo éleos normalmente para traduzir a misericórdia e a compaixão de Deus, indicadas como hesed e rahămîm (BULTMANN, 1967; SIMIAN-YOFRE, 2008). É óbvio que a misericórdia divina precede a nossa e nos leva a praticá-la, como nos indica Mt 18,33 ("não devias, também tu, ter misericórdia do teu companheiro, como eu tive misericórdia de ti?") e Tg 2,13 ("porque o julgamento será sem misericórdia para aquele que não pratica a misericórdia"). Também é certo que em $\mathrm{Rm}$ 12,8; Tg 3,17 e Jd 22 a éleos de Deus compreende a benignidade em geral. Mas o mesmo termo também pode ser entendido como graciosa fidelidade de Deus, como em Lc 1,58; Rm 11,30; Ef 2,4 e 1Pd 1,4. E é certo que é a éleos de Deus que vai triunfar no juízo, como vemos em Mt 5,7; 2Tm 1,18; Jd 21; Tg 2,13. O contrário de éleos é anéleos (BULTMANN, 1967), que significa sem misericórdia ou impiedoso, como encontramos em Tg 2,13. Se o termo éleos ocorre quase 400 vezes na Septuaginta, para traduzir o hebraico hesed ou rahămîm, no NT a ocorrência é bem diversificada, visto que éleos e seus derivados ocorrem 78 vezes em todo o NT, distribuídos assim: 26

1 Aliás, é salutar recordar como, na antiga Sequência Dies Irae, a Igreja professa a gratuidade salvífica da misericórdia de Deus: "Rex tremendae majestatis, Qui salvandos salvas gratis, Salva me, fons pietatis" ("Rei de imensa majestade, que salvando, salvas na gratuidade, salva-me, fonte de piedade"). 
vezes em Paulo; 20 vezes em Lucas e Atos; 15 vezes em Mateus, 5 vezes em Marcos, 2 vezes em Hebreus, 4 vezes em Tiago, 3 vezes em Pedro, 2 vezes em Judas, 1 vez em 2João. E o grupo está completamente ausente somente de João, Filipenses e 1-2 Tessalonicenses.

Em segundo lugar, o termo eleếmōn (BULTMANN, 1967), que significa misericordioso, no sentido de ter compaixão, aparece como uma característica de Cristo em $\mathrm{Hb}$ 2,17. Cristo louva os eleémōnes em Mt 5,7 ( $1^{\mathrm{a}}$ ocorrência no NT: misericordiosos), termo que encontramos igualmente na Did 3,8 (DIDAQUÉ, 1950) e na 2Clem 4,3 (CLEMENTE ROMANO, 1950, p. 358). Cristo também convida seus seguidores a serem "misericordiosos como o Pai do céu é misericordioso" (Lc 6,36). Aliás, a prática das obras de misericórdia sempre foi uma constante na vida da Igreja (KASPER, $2014)^{2}$.O contrário de eleếmōn é aneleếmōn para indicar "sem compaixão", como entramos em Rm 1,31 (BULTMANN, 1967).

Em terceiro lugar, também temos o termo eleēmosýne (BULTMANN, 1967), que é usado tanto no NT como no AT, na prática da misericórdia no sentido de dar esmolas, como encontramos em Mt 6,2-4, Lc 11,41 e At 3,2-10. A Septuaginta usa o termo para traduzir a justiça e a compaixão de Deus, indicadas como ședāqâ ou ședeq (BULTMANN, 1967). O termo eleēmosýne também pode ser usado para a prática de benevolência, no sentido de praticar obras de misericórdia e caridade. Juntamente com o jejum e a oração, o dar esmolas era uma prática comum para a piedade entre judeus (Mt 6,14) e entre cristãos (Did 15,4) (DIDAQUÉ, 1950). Aliás, o dar esmola, enquanto prática da caridade, é louvado em At 9,36, presente nas muitas "boas obras e esmolas" de Tabita, em Jope. Cristo adverte contra o seu mau uso a serviço da vaidade pessoal, apenas para receber a recompensa dos outros, como encontramos em Mt 6,2-3, alertando contra a hipocrisia do "fazer para aparecer" e Did 1,6 adverte contra o dar esmolas de forma impudente (DIDAQUÉ, 1950).

\subsection{Corpus Sinopticum}

Nos Sinóticos eleéō ocorre sobretudo nos textos de narrativas. As exceções aparecem em Mt 5,7; 18,33; Lc 10,37; 16,24. Na ocorrência de éleos se dá o contrário, visto que se emprega somente em texto de diálogo, com exceção de Lc 1,58.

a) $\mathrm{O}$ verbo eleéo (ser misericordioso, agir com misericórdia, praticar a misericórdia) é usado para as situações de erupção da misericórdia divina no meio da realidade da desgraça humana (BULTMANN, 1967, p. 411-414). Esta obra foi levada a cabo na pessoa de Jesus Cristo, o homem de Nazaré, que opera a salvação, cura e libertação por meio de suas obras e de sua própria autoridade. Por exemplo, Jesus é aquele que atende ao pedido de socorro do cego de Jericó: "Filho de Davi, tem misericórdia/compaixão de mim" (Mc 10,47-48; e paralelos Mt 9,27; 15,22; 17,15; 20,30; Lc $17,13 ; 18,38-39)$. É oportuno recordar que em tais ocasiões, geralmente, Cristo é

2 Obras de Misericórdia Corporais: (1) dar de comer a quem tem fome; (2) dar de beber a quem tem sede; (3) vestir os nus; (4) acolher os peregrinos; (5) visitar os doentes; (6) visitar os presos; (7) enterrar os mortos. Obras de Misericórdia Espirituais: (1) dar bons conselhos; (2) ensinar os ignorantes; (3) corrigir os que erram; (4) consolar os aflitos; (5) perdoar os que nos ofenderam; (6) suportar com paciência as fraquezas do nosso próximo; (7) rezar a Deus pelos vivos e pelos mortos. 
chamado com os títulos messiânicos: "Filho de Davi" ou "Mestre", já que o título $m a$ teano "Kyrios" é pós pascal. Assim, a exclamação "Senhor, tem misericórdia" é uma confissão de fé na divindade de Jesus Cristo.

b) A misericórdia do homem para o homem é imagem da misericórdia divina e aparece poucas vezes nos Sinóticos, mas é significativo que isso represente o ideal de vida para quem quer seguir o Cristo: em Mt 5,7 "os misericordiosos receberão a misericórdia de Deus", com emprego do verbo na voz passiva; em 18,33, onde a misericórdia do servo incompassivo se baseia na compaixão ilimitada de seu senhor; em Lc 16,24 , o rico, que em sua vida tinha sido incompassivo e que invoca, em seus sofrimento, a misericórdia de Abraão e lhe coloca a situação limite de tempo. Estes e muitos outros textos bíblicos são claros e objetivos: o homem é chamado a agir com misericórdia para com o seu semelhante, cuidando do outro com bondade e compaixão, "na reciprocidade das relações humanas" (BULTMANN, 1967, p. 411). A motivação é, sem sombra de dúvidas, a misericórdia do próprio Deus, que promete a sua misericórdia divina aos que forem misericordiosos para com os outros (Mt 5,7). Aliás, o grande convite de Cristo a todos nós é: "sede misericordiosos como o vosso Pai celestial é misericordioso" (Lc 6,36).

c) Do mais, o que encontramos em Mateus e Lucas são as ocorrências de Jesus que, em suas controvérsias com os fariseus, dá testemunho da misericórdia de Deus, que não se baseia em pormenores rituais e sim respostas diante da dor e do sofrimento humano, sendo sempre solidário e ajudando a todos em suas necessidades (saúde, fome, sede, pecados etc.), indicando que o caminho para promover e cuidar bem da vida própria e do próximo é agindo com o amor das entranhas (splanchna) misericordiosas do Pai ou, dito de outra forma, "de uma misericórdia proveniente do coração" (KÖSTER, 1979, p. 906). Bastaria que olhássemos para o texto de Mt 23,23 (formalismo casuístico) e de Lc 10,37 (Bom Samaritano) (BULTMANN, 1967). Aliás, aqui queremos nos deter um pouco sobre três textos e exemplos de misericórdia, a partir do Evangelho de Lucas, como que num estudo de caso, para melhor entender a promoção e o cuidado da vida por meio da prática da misericórdia e da bondade com os mais fragilizados, três encontros que resgatam, cuidam e promovem a vida:

1. O texto de Lc 1,46-80, do encontro entre Maria e Zacarias: entrando na casa de Zacarias, Maria engrandece e louva o Senhor porque agiu com misericórdia e afirma que esta será lembrada de "geração em geração", como que um marco do agir de Deus na história (MEYNET, 1994; GRASSO, 2019), em defesa da vida, integrando três realidades de Deus "sua potência, sua santidade e sua misericórdia" (FITZMYER, 1987a). Aqui a ideia é aquela veterotestamentária de hesed como misericórdia-fidelidade de Deus, que é assumida no Novo Testamento (ZOBEL, 2003; BULTMANN, 1967), que estava cumprindo o que tinha prometido, promovendo e resgatando vidas. Maria é capaz de ver em tudo isso a bondade e a fidelidade de Deus não apenas para com ela e sim para com todo Israel de Deus, pois é capaz de ver "o amor em extensão", sem barreiras e limites, abarcando todas as gerações (PÉREZ MILLOS, 2017), sendo algo extrínseco de Deus, seu "estilo salvífico e libertador", gerador e promotor de vida (GRASSO, 2019). Neste mesmo capítulo e cena temos Zacarias, aliás, na mesma casa, que bendiz e louva a Deus por ocasião do nascimento de seu filho João Batista, porque Deus usou de misericórdia para com eles, "lembrando-se de sua aliança", feita anteriormente aos pais, tirando-o da situação de não continuidade da vida pela descendência que não vinha e agora veio (PÉREZ MILLOS, 2017). Aqui a misericórdia é fidelidade de Deus à sua promessa feita a nossos pais, conforme prometera antes. E neste sentido, 
poderíamos dizer que a misericórdia vem em cumprimento das promessas: ela resgata, promove a vida e não decepciona. Pelo contrário, a misericórdia fortalece a esperança de que a bondade do Senhor irá reinar um dia, mesmo diante das situações mais difíceis da vida como esta que estamos enfrentando diante das angústias com a pandemia do coronavírus (COVID-19). O Deus justo e santo é misericordioso e o seu poder se manifesta sobretudo no perdão e na misericórdia, capazes de resgatar e promover a vida de todos fragilizados, pois isso lhe é característica própria: defender a vida, por meio da misericórdia (GRASSO, 2019). Em suma, a justiça de Deus se manifesta em sua misericórdia, que é fidelidade à sua promessa feita a nossos pais (PÉREZ MILLOS, 2017), conforme prometera antes, mas que se realiza na concretude "do aqui e agora" (DILMANN; MORA PAZ, 2016, p. 52). Essa é a forma de Deus cuidar de nós e pede que façamos a mesma coisa em relação ao próximo, especialmente para com os mais pobres (FITZMYER, 1987a; DILMANN; MORA PAZ, 2016).

2. O texto de Lc 10,25-37, do encontro do bom samaritano com o judeu ferido e caído por terra: após o sacerdote e o levita passarem e ignorarem aquele judeu ferido que estava caído por terra e que necessitava de misericórdia, eis que um samaritano é capaz de ser-lhe solidário, sendo-lhe próximo e misericordioso, sem preconceitos, mas com olhar e ações de compaixão (splanchnizomai), movido pela misericórdia (PÉREZ MILLOS, 2017; GRASSO, 2019), fazendo-lhe romper barreiras, curando e promovendo a vida (DILMANN; MORA PAZ, 2016). De tal forma que a misericórdia nos leva a uma aproximação de quem mais precisa (MAZZAROLO, 2016), e não o contrário, ou seja, ela não nos afasta das pessoas; ela promove a vida e não ignora as necessidades dos mais fragilizados, sejam eles quem forem e estejam na situação que estejam. Aqui a "compaixão" é a grande protagonista que realiza todo o movimento em prol do resgate da vida do próximo ferido, fragilizado e abandonado (FITZMYER, 1987b). Quem age com misericórdia é capaz de curar as feridas de seu semelhante (MEYNET, 1994), mesmo não o conhecendo, como diz o ditado popular: "fazendo o bem, sem olhar a quem", sendo agente de bondade e "dando testemunho da misericórdia de Deus" (BULTMANN, 1967, p. 412); é capaz de sentir compaixão e aproximarse de quem precisa usando da medicina da misericórdia, ajudando o outro a ter vida plena, a retomar sua vida, a sentir-se amado e protegido em sua vida, que estava ferida e machucada, abandonado ao longo de uma estrada sem perspectivas. A misericórdia tem um processo intrínseco de abertura e aproximação, capaz de promover a vida (PÉREZ MILLOS, 2017). Nesse sentido, a misericórdia nunca aumenta a dor de quem já está chagado e caído por terra, mas a alivia e a estanca, com faixas plenas de amor, bondade e gratuidade, a fim de que o outro recupere o dom de sua vida plenamente, pois o amor ama sem definir seu objeto (FITZMYER, 1987b). Se for o caso, paga por isso. Pois sabe que pode e deve ajudar o outro, aproximando-se dele e envolvendo-o misericordiosamente. Assim como o samaritano usou de misericórdia para com aquele homem ferido, curou suas feridas e provou sua vida, só nos resta "ir e fazer a mesma coisa" (Lc 10,37), praticar e exercitar a misericórdia (GRASSO, 2019), como forma de resgatar e promover a vida dos mais fragilizados.

3. O texto de Lc 15,11-32, do encontro do pai compassivo com o filho pródigo, uma das três parábolas do tríptico da misericórdia, do perdido e do encontrado (FITZMYER, 1987b; MEYNET, 1994). Este é um texto onde não aparece a palavra "misericórdia", mas a misericórdia divina se acha expressa de modo muito evidente e claro, visto do gesto de superlativa bondade do pai misericordioso (GONZAGA, 2016). Não temos a terminologia, mas contribui a analogia. A terminologia usada aqui em Lc 15 é 
o verbo splanchnizomai, no passivo, que expressa "o gesto de ser movido pela compaixão" (MAZZAROLO, 2016, p. 79; KÖSTER, 1979, p. 923; FITZMYER, 1987b, p. 682), ou ainda, de "compadecer-se" e de "comover-se" desde as entranhas misericordiosas (PÉREZ MILLOS, 2017; GRASSO, 2019). Aliás, essa terminologia permitenos compreender ainda mais e melhor o mistério da misericórdia divina que se desenrola entre o amor do pai e o erro do filho, que age com prodigalidade, porém busca e obtém o perdão na gratuidade e na compaixão de seu pai, que o acolhe com um abraço terno e restaurador (GONZAGA, 2016.; DILMANN; MORA PAZ, 2016). O amor misericordioso do pai é um amor visceral, quase que uterino, incondicional, aberto e ilimitado (FITZMYER, 1987b), capaz de debruçar-se sobre seu filho que se sente revalorizado e resgatado em sua vida, que estava como que perdida. O pai não teve dúvida em resgatar a vida do filho que "estava morto, como filho e como homem" (MEYNET, 1994, p. 468), de amá-lo e promovê-lo, de trazê-lo novamente à vida. Assim podemos dizer que para Cristo, a misericórdia não condena e sim revitaliza, reconduz à vida, mesmo que esta tenha sido muito ferida e machucada pelos muitos erros e pecados ao longo do percurso de cada um. Pelo contrário, o que foi atingido pela misericórdia se sente reencontrado, recuperado, resgatado e "volta à vida" (DILMANN; MORA PAZ, 2016, p. 378). O olhar misericordioso do Pai é penetrante e cheio de compaixão, e é capaz de reavaliar tudo a partir do amor que sabe promover a vida e não humilhar, sabe tirar o bem mesmo da experiência do mal sofrido por seu filho. Sua conduta amorosa é sua pedagogia de reconstrução e cuidado da vida de seus dois filhos, indistintamente (GONZAGA, 2016). Neste e em tantos outros sentidos a misericórdia se faz necessária em nossos dias, pois o mal tem nos afetado em nosso ser e existência. Ela é a forma sublime de Deus cuidar de seus filhos e filhas, com amor e bondade, e, tendo equilíbrio com a ética, "a restaurar, a vivificar e devolver à vida aquilo que estava morto" (MAZZAROLO, 2016, p. 89).

\subsection{Corpus Paulinum e Hebreus}

Paulo quis ser lembrado como um homem que se tornou Apóstolo por pura misericórdia de Cristo (ēleēthēn: recebeu misericórdia, na voz passiva) (BULTMANN, 1967), como lemos em 1Tm 1,13-16 (aliás, temos 8 ocorrências nas Cartas Pastorais: 3 vezes na 1Tm; 3 vezes na 2Tm e 2 vezes em Tt), confirmada pela ideia de 1Cor 15,910, que fala da gratuidade de Deus em sua vida; ou ainda, que se tornou digno de confiança "como tendo recebido misericórdia do Senhor" (1Cor 7,25).

Tendo em vista que boa parte de Israel recusara o Evangelho, Paulo se esforça em Romanos (8 ocorrências) para deixar claro que a livre misericórdia de Deus não era uma contradição de sua misericórdia em relação à Aliança $(\mathrm{Rm}$ 9,15-18). Aliás, Paulo afirma que o Plano Divino da Salvação passou para os gentios (Rm 9,23-24; 11,30; $15,9)$, sem nunca ter deixado de ser dos judeus (Rm 11,31) e, que, portanto, é de ambos (Rm 11,32), alargando a visão acerca da misericórdia de Deus (BULTMANN, 1967), que cuida e promove a vida de todos e não apenas dos judeus.

Paulo não tem dúvidas em lançar a exortação para todos: "sede uns para com os outros bondosos e compassivos, misericordiosos, perdoando-vos mutuamente, como Deus em Cristo vos perdoou" (Ef 4,32); a "falta de misericórdia/piedade" se encontra no final e fechamento da lista das atitudes de falta de conhecimento de Deus (Rm 1,2932), que é igualmente fechamento à vida. Aliás, Paulo não tem dúvidas em ter feito a experiência das entranhas (splanchna) misericordiosas do Pai e "mantém válido um 
dos elementos essenciais do sentido originário do termo, enquanto splanchna indica toda a personalidade tocada e marcada em sua intimidade mais profunda" (KÖSTER, 1979, p. 923-926), como alguém que foi marcado profundamente pelo amor misericordioso do Pai, transformando sua vida.

Em 2Tm 1,16, o autor da carta fala da misericórdia de Deus como uma dádiva para a "família de Onésimo, que agiu com coerência e bondade". Por isso mesmo, Paulo lhe augura "encontrar misericórdia no Dia do julgamento, diante do Senhor" (2Tm 1,18). Enfim, Paulo não tem dúvidas em afirmar que a salvação dos que têm fé se baseia pela pura misericórdia de Deus "pela fé em Cristo Jesus" e não "pelas obras da lei" (Gl 2,16; Rom 3,20; Ef 2,4-9; Tt 3,5). O Apóstolo também não tem dúvidas de que o cristão tem que repassar a misericórdia que recebeu $(2$ Cor 4,$1 ; \mathrm{Rm} 12,1)$, pois somente resgata, cura e promove a vida plenamente.

Em Hebreus, que não é citada entre as cartas católicas, mas também não é paulina, ao falar do Sumo Sacerdote do AT e de suas funções no Dia da Expiação (Lv 16), a fim de mostrar a solidariedade de Cristo com seus irmãos, o autor da carta mostra a garantia de uma compreensão misericordiosa e ilimitada de Cristo (Hb 2,17; 4,15), dando à Igreja, sem esperança, a confiança de se aproximar do trono da graça a fim de encontrar graça $(\mathrm{Hb} 4,16)$, alcançando a misericórdia e, com ela, a vida. Além de que quem desrespeitar a Lei Mosaica "morre sem misericórdia", mas julgados apenas pelo testemunho de duas ou três pessoas (Hb 10,28).

\subsection{Corpus Joannicum}

No Evangelho de João o termo misericórdia está totalmente ausente. O que temos são termos nas Cartas e no Apocalipse. Aliás, o livro do Apocalipse procura convencer a Igreja de Laodiceia de sua condição "lastimável" (eleeinos), indicando uma igreja sem misericórdia, a respeito de suas riquezas terrenas e não cuidado da vida dos mais fragilizados, e a coloca sob o julgamento de Cristo, único verdadeiro e válido (Ap 3,17). A 2Jo 3 apenas menciona a misericórdia na saudação inicial, como que expressando um desejo: "convosco estarão a graça, a misericórdia e a paz". Mas realmente os termos éleos (misericórdia), eleéo (agir com misericórdia), eleếmōn (misericordioso), eleèmosýne (prática da misericórdia, dar esmolas), splanchnizomai (movido por compaixão), estão ausentes do corpus joanino, que apresenta outros termos para a realidade, o cuidado e a defesa da vida, a exemplo de: agape (amor), agapaō (amar), bios (vida), $z \bar{o} \bar{e}$ (vida), como veremos no tópico 3 deste artigo: vida no NT.

\subsection{Corpus Catholicum}

O conjunto das Epístolas Católicas, o menos estudado do NT e o mais discutido desde os tempos antigos sobre sua presença no Cânon do NT, não deixa passar despercebido o tema da misericórdia de Deus e de sua justiça em termos de julgar nosso viver, de testemunhar a fé e de nos pedir que ajamos com misericórdia no cuidado da vida de nossos irmãos, especialmente os mais fragilizados. Aqui neste artigo são computamos apenas as cartas de Tiago, Pedro e Judas, porque as três cartas de João são analisadas no corpus joanino.

a) Tiago $(2,13)$ faz uma igreja insensível e indiferente entender que a misericórdia que se pratica aqui na terra tem seus efeitos no julgamento final, pois "o juízo é sem 
misericórdia ao que não pratica misericórdia". Mas ele reconhece que a "a misericórdia triunfa no julgamento". Este mesmo tema nós também encontramos em Lc 16,24-25; Mt 18,33-34; 25,40-45. E em 3,17, Tiago afirma que a Sabedoria, entre outras virtudes, é plena de misericórdia, capaz sempre de promover e cuidar da vida.

b) 1 Pedro $(1,3)$ inicia sua carta louvando "a grande misericórdia de Deus Pai que agiu por meio da ressurreição de Jesus Cristo e nos gerou de novo para uma esperança viva”, em consonância com Ef 2,4 e 1Cor 15,19. Se não bastasse isso, 1Pd 3,8 convida a todos para: "finalmente, sede todos unânimes, compassivos, cheios de amor fraterno, misericordiosos e humildes de espírito".

c) Judas (v.1), após desejar que "a misericórdia, a paz e a caridade" sejam concedidas abundantemente a seus destinatários, e depois de falar do amor de Deus, que seus leitores experimentaram, fala da expectativa que eles têm de um julgamento misericordioso por meio de Jesus Cristo e os anima e incentiva a viver e agir com misericórdia para com os que vivem com eles e ao redor deles (vv.21-23). Aliás, Judas também menciona a trilogia "fé, esperança e misericórdia" (vv.20-21).

\section{Vida no Novo Testamento}

Se foi analisada amiúde a misericórdia no Novo Testamento mediante a palavra éleos e seus derivados no tópico anterior, deve-se lembrar que este termo grego traduz predominantemente na Septuaginta o hebraico hesed (ZOBEL, 2003), este último tendo como proposta de tradução justamente amor, especialmente no livro do profeta Oseias (LIMA; BOUZON, 1990). Por isso, algumas traduções modernas optaram por verter o refrão do Sl 136 dessa forma: "Rendei graças a YHWH, porque ele é bom, porque para sempre (dura) seu amor". Isto aponta o entrelaçamento, já no Antigo Testamento, entre as ideias de amor e misericórdia.

Não obstante, amor é traduzido dentro do Novo Testamento predominantemente pela palavra agape e pelo verbo agapaō. Se tanto a palavra quanto o verbo não possuem significados especiais na Septuaginta, dentro do Novo Testamento passa a ter um sentido teológico de suma importância: o amor elevado de Deus, o qual proporciona que os seres humanos o experienciem. Diferencia-se, portanto, de outro verbo para amor: phileō, o qual denota um sentimento de amizade, de associações íntimas e próximas, enfim uma afeição - não necessariamente o "amor superior" vindo da parte de Deus (DANKER; BAUER, 2000).

Este amor manifesta-se de forma mais específica na vida, $z \bar{o} \bar{e}$, que Cristo proporciona aos seus fiéis. As três palavras, éleos, agapē, e zōē encontram-se em Jd 21: "Guardai-vos no amor de Deus, esperando a misericórdia do nosso Senhor Jesus Cristo para a vida eterna". Aqui, o caminho proposto é justamente este: o amor é um meio para se obter a misericórdia, culminando na vida. Como declara Bauckham (1998, p. 114): "não indica uma atitude meramente passiva, mas uma orientação da inteira vida em direção à esperança escatológica".

Se no grego faz-se uma distinção clássica entre $z \bar{o} \bar{e}$, que significa "vida como força vital e natural"; e bios, que tem um conteúdo ético mais forte, significando também "modo de vida", este último é surpreendentemente raro no Novo Testamento, com três significados: o temporal ( $1 \mathrm{Pd} 4,2-3 ; 1 \mathrm{Tm} 2,2 ; 2 \mathrm{Tm} 2,4)$; riquezas, fortuna (Mc 12,44; Lc 15,12.30; 21,4; 1 Jo 3,17); e "modo de vida", de modo indireto, em Lc 8,14 e 1 Jo 2,16 (LINK; ZABATIERO, 2000). Em contrapartida, compreende-se $z \bar{o} \bar{e}$ como 
uma força vital divina que governa toda criatura viva, e a qual é buscada pelos homens em oração (BERTRAM; BULTMANN; VON RAD, 1964). É este termo grego que será analisado agora.

\subsection{Corpus Sinopticum}

O verbo zāo, "viver", ocorre escassamente nos Sinóticos, com 6 vezes em Mateus, 3 em Marcos e 9 em Lucas. O substantivo segue um padrão similar: ocorre 7 vezes em Mateus, 4 em Marcos e 5 em Lucas. Em Mateus há uma utilização apocalíptica: ele usa o substantivo $z \bar{o} \bar{e}$, junto com "Reino dos céus" ou "alegria", etc., como uma expressão de salvação escatológica, a qual primeiramente serve à ética, de tal forma que a recompensa prometida para as ações justas é a vida eterna (SCHOTTROFF, 1991). O substantivo $z \bar{o} \bar{e}$ é empregado apenas ocasionalmente, sem qualquer frase qualificadora, indicando que semelhante vida é considerada real e verdadeira, a própria vida de Deus mesmo, que pode ser visto em passagens como Mt 18,18; Mc 9,43.45 (LINK; ZABATIERO, 2000). Nos Sinóticos a pregação de Jesus faz referência apenas ao aspecto futuro da $z \bar{o} \bar{e}$, desde que a pregação ainda não olha para trás, para a morte e ressurreição como eventos que determinam o presente (BERTRAM; BULTMANN; VON RAD, 1964).

Chama a atenção o evangelho de Lucas, que fala de vida num sentido fortemente teológico em dois aspectos: a da ressurreição e a da conduta correta. A ressurreição significa que a sarx, "carne" de Jesus não é deteriorada (At 2,27.31; 13,35), os discípulos podiam realmente tocá-lo (Lc 24,36-43). A vida do ressuscitado significa, acima de tudo, que ele de fato é novamente uma vida física, a exemplo do que ocorreu com Tabita e Êtico (At 9,$41 ; 20,12$ ). Por isso Jesus julgará tanto os vivos quanto os mortos (At 10,42; 17,30-31) (SCHOTTROFF, 1991).

Ainda na visão lucana, o caminho da vida é metanoia: "deu mudança para a vida" (At 11,18; 13,38) (DANKER; BAUER, 2000, p. 640). Lucas utiliza "morte" e "vida" num sentido metafórico (Lc 15,24.32): metanoia e perdão dos pecados são etapas da morte para a vida. A mensagem de Cristo é a mensagem da vida (At 5,20), e por isso é inconcebível para Lucas matar o "autor da vida" (At 3,15), ou procurar o vivo entre os mortos (Lc 24,5) (SCHOTTROFF, 1991). Em outras palavras, Cristo é o modelo "perfeito" para a vida.

\subsection{Corpus Paulinum e Hebreus}

Das 140 ocorrências do verbo zāo, a maioria (59 vezes) concentra-se no corpus paulinum, especialmente na Carta aos Romanos, com 23 vezes (SCHOTTROFF, 1991). Paulo, que pensa no poder do pecado em termos radicais, também entende vida, a salvação que Cristo torna possível, num total e compreensível sentido: a pessoa na sua totalidade, como sōma, "corpo", é libertada (Rm 6,12-14) e todas as pessoas são objeto da ação salvífica divina $(\mathrm{Rm} 5,18)$. Vida é existência ilimitada, "vida eterna" (Rm 6,22), ressurreição dentre os mortos (1Cor 15,21), Paulo pensa apocalipticamente (SCHOTTROFF, 1991).

O conceito de Paulo da vida eterna é profundamente afetado pela ressureição de Cristo (1Cor 15,4), a qual comprova o poder da vida divina sobre a morte (Rm 14,9), concretização do poder vivo de Deus $(2$ Cor 13,4$)$. Mediante sua ressurreição, Cristo 
tornou-se o último Adão, autor de uma nova vida para a humanidade (Rm 5,12; 1Cor 15,20). A vida do cristão não é a sua própria, mas a de Cristo (Gl 2,20; Fl 1,21; 2Cor $4,10)$. Uma vida justificada por Cristo ( $\mathrm{Rm} 5,18)$, transmitida pela "palavra da vida" (Fl 2,16; 2Tm 1,10; Tt 1,2-3), operada mediante o Espírito Santo (Rm 6,4) (LINK; ZABATIERO, 2000). Por isso o terror da morte não é necessariamente morrer, mas antes inabilidade em realizar a vida. Essa inabilidade, da qual Paulo fala com horror, é a inabilidade de executar a vontade de Deus. Vida debaixo do pecado é uma tentativa de busca da vida, a qual produz senão morte (Rm 7,16.22) (SCHOTTROFF, 1991).

Nesta nova vida do cristão, há uma tensão entre o presente e o futuro: sua nova vida já existe, mas ainda não foi plenamente manifestada (Cl 3,3-4) (LINK; ZABATIERO, 2000). A nova vida não se limita ao tempo histórico, mas sim indica o futuro quando for vencido o último inimigo: a morte (1Cor 15,26.28; Rm 6,22; Gl 6,8). A transição do temporal para o eterno é retratada pela transformação milagrosa, o arrebatamento (1Cor 15,20; 1Ts 4,13-17) (LINK; ZABATIERO, 2000). Por isso presente e futuro em Paulo não podem ser separados, seja temporal ou materialmente. Somos " $v i$ vos como dentre os mortos" ( $\mathrm{Rm} 6,13)$; morremos para o pecado mediante o batismo $(\mathrm{Rm} 6,2.11)$, e vivemos na esperança da ressurreição dos mortos $(\mathrm{Rm} 8,24)$. Vivemos $(\mathrm{Rm} 6,4.11 ; 8,2.6 .10)$, e viveremos ( $\mathrm{Rm} 1,17 ; 2,7 ; 5,17.21 ; 8,11.13)$, somos libertos e seremos libertos (Rm 6,18.22; 8,21) (SCHOTTROFF, 1991).

A presença da vida pode ser vista na palavra pregada como um acontecimento histórico, o qual distribui vida (2Cor 2,16; 5,18-20), "o poder de Deus para a salvação" $(\mathrm{Rm} 1,16)$, a palavra da vida ( $\mathrm{Fl} 2,16)$. Por isso, nas cartas Pastorais pode ser dito que o Evangelho destrói a morte e manifesta a vida $(2 \mathrm{Tm} 1,10$; Tt 1,2) (BERTRAM; BULTMANN; VON RAD, 1964). É por essa razão que Paulo pode dizer que a vida que agora tem não é propriamente dele, pois Cristo vive nele (Gl 2,19; Rm 8,10), ou seja, Cristo é a vida em nós (2Cor 4,10), ou que nós vivemos em Cristo (Rm 6,10), ou que devemos viver nele (2Cor 13,4), pois Cristo é a nossa vida $(\operatorname{Rm~} 8,2)$ (BERTRAM; BULTMANN; VON RAD, 1964).

O escrito aos Hebreus segue a linha paulina: para ele, através da morte e ressurreição de Cristo evidenciou-se que o poder da morte não é absoluto, pois Cristo concede vida a partir da morte a todos que responderem com fé (Hb 2,15) (KOESTER, 2008). O Deus vivo $(\mathrm{Hb} 3,12)$ possui uma palavra viva $(\mathrm{Hb} 4,12)$ : portanto, desde que possui a vida, é capaz de conceder vida, obtida convertendo-se do pecado para servir este Deus vivo, condição submetida ao escrutínio da Palavra (KOESTER, 2008). Aproveitando a comparação com Melquisedec, afirma ser o Filho de Deus sem fim de vida (Hb 7,3), o que combinado ao fato de não possuir genealogia sugere ser verdadeiramente Deus, e não meramente um mortal divinizado; e, conforme de declarado em S1 90,2 sem início ou fim pode ser afirmado apenas por Deus (KOESTER, 2008). O caminho proposto por Cristo não é apenas novo, mas vivo (Hb 10,20), apregoado semelhantemente às estradas abertas pelos imperadores romanos, "inaugurado" por um Cristo vivo ( $\mathrm{Hb}$ 7,8.25) e que conduz ao Deus vivo (Hb 9,14; 10,31; 12,22) (KOESTER, 2008).

Enfim, há ainda o uso de zōopoieō em Rm 4,17; 8,11; 1Cor 15,22.36.45; 2 Cor 3,6; Gl 3,21. Significando "fazer viver" num sentido soteriológico, onde o sujeito é naturalmente Deus, Cristo ou o espírito. Afirma-se, portanto, que a Lei não pode dar vida em si mesma (Gl 3,21), atributos exclusivos de Deus (Rm 8,11) e Cristo (1Cor 15,22) (BERTRAM; BULTMANN; VON RAD, 1964). 


\subsection{Corpus Joannicum}

Um levantamento estatístico demonstra o quanto o conceito de "vida" é importante nos escritos joaninos. No Evangelho de João o substantivo zōē ocorre 36 vezes, enquanto o verbo zaō 16 vezes. Em 1Jo o substantivo ocorre 13 vezes, mas o verbo uma única vez (1Jo 4,9). No Apocalipse o verbo ocorre 15 vezes e o substantivo 17 vezes. Ainda ocorrem os verbos compostos: zōopoieō, 3 vezes no Evangelho (Jo 5,21 2x e 6,63); e anazaō, em Ap 20,5, através de uma leitura da versão erasmiana, sem comprovação encontrada em manuscritos (LINK; ZABATIERO, 2000). ${ }^{3}$

Quando se compara com os Sinóticos, há uma mudança significativa: se nos Sinóticos o tema predominante é o do Reino de Deus (que ocorre apenas três vezes em João), há uma ênfase joanina na vida de tal forma que se descobre que esta, na verdade, pertence à mesma categoria teológica, tornando-a sinônimo do "Reino de Deus" sinótico (LINK; ZABATIERO, 2000).

No Evangelho de João, a vida é concebida em termos "revelatórios"; qualquer um que receba a palavra de Jesus "passou da morte para a vida" (Jo 5,24), não verá ou experimentará a morte para sempre (Jo 8,51; 11,26). É um conceito tomado do evento da morte física, pois o crente vive além da morte física. E transcender a morte não significa imortalidade (Jo 8,52). João utiliza as palavras "vida" e "morte" num duplo sentido: apenas num modo subordinado a morte física é intencionada. O maior milagre de Jesus não é conceder vida física, a qual possui uma importância secundária, mas sim vida verdadeira ao crente (Jo 11,26) (SCHOTTROFF, 1991). Os "mortos", para João, constituem aqueles que não possuem a vida verdadeira; estes, portanto, precisam ouvir a voz do Filho de Deus, ou seja, aceitar sua palavra, e então viverão (Jo 5,25). O próprio Jesus é vida no sentido de que ele é o doador da vida, à medida que revela a si mesmo no Pai (Jo 11,25; 14,6) (SCHOTTROFF, 1991).

Não há dualismo entre vida espiritual e física, e sim o dualismo tipicamente joanino escatológico entre vida e morte. Nesta concepção, há somente uma vida verdadeira, a de Deus, e somente os que recebem a Cristo usufruem dela (Jo 10,10) (LINK; ZABATIERO, 2000). A vida é qualificada por aiōn, "eterna" (Jo 4,14; 6,51; 10,28), a vida que pertence à era futura, sem excluir a quantidade de tempo dessa vida, dentro da linha de pensamento veterotestamentário, uma vida cuja duração não tem fim. Por isso, no Evangelho e na primeira Carta, o peso das ocorrências cai sobre o aspecto presente da vida eterna (Jo 3,36; 6,63; 12,49); a vida eterna consiste em conhecer a Deus (Jo 17,3) (LINK; ZABATIERO, 2000).

Uma outra peculiaridade de João; a vida não depende especificamente do evento pascal, pois ela é verdade já "no princípio" (Jo 1,1) (SCHOTTROFF, 1991). Desde que a promessa futura não se refere ao futuro escatológico, mas ao momento da decisão quando confrontado com a palavra, aquele que crê, este viverá. Esta vida possui um futuro eterno (Jo 4,14; 6,27; 12,25) (BERTRAM; BULTMANN; VON RAD, 1964). A vida do crente, ainda, é evidenciada como estando sob o amor. Para permanecer em Cristo (Jo 15,1-8), precisa permanecer em amor (Jo 15,9-17). O amor é a manifestação externa dessa vida (BERTRAM; BULTMANN; VON RAD, 1964).

3 Sobre a leitura erasmiana, Danker; Bauer (2000, p. 62). Esse termo, segundo o texto crítico da NA28, ocorre apenas em Lc 15,24 e Rm 7,9. 
Em Apocalipse a salvação no mundo por vir, vislumbrada pelo vidente, significa estar registrado no livro da vida (Ap 13,8; cf. 3,5; 17,8; 20,12, 15; 21,27), de que alguém pode beber da água da vida (Ap 22,17; cf. 21,6; 7,17;22,1) e pode comer da árvore da vida (Ap 2,7; 22,2, 14, 19), e que terá acesso à coroa da vida, a coroa da vitória dos mártires (Ap 2,10) (SCHOTTROFF, 1991).

\subsection{Corpus Catholicum}

Dentro do corpus catholicum merece atenção especial a primeira carta de Pedro, onde o presente é governado pela elpis, "esperança”, ancorada nos eventos salvíficos, e por isso pode ser descrita como "viva", desde que Deus nos gerou novamente mediante a ressurreição de Cristo (1Pd 1,3) (BERTRAM; BULTMANN; VON RAD, 1964). $\mathrm{O}$ uso de zōopoiē em 1Pd 3,18, apenas aqui em todo o Novo Testamento no sentido da ressurreição de Cristo, ao contrário de outras passagens que salientam a futura ressurreição geral (Jo 5,21; Rm 4,17; 8:11; 1Cor 15,22), mostra que a ressurreição já é uma realidade presente, factível através de Cristo (MICHAELS, 1998). Aqui neste tópico do artigo repete-se o fato acima, ou seja, analisamos entre as cartas católicas apenas as cartas de Tiago, Pedro e Judas, visto que as três cartas de João são analisadas no corpus joanino.

Uma importante passagem, que mostra a misericórdia como proposta de vida, encontra-se em 1Pd 3,8-12. Utilizando a palavra eusplanchnos, "entranhável misericórdia", um hápax legomenon (somente aqui e Ef 4,32) que pertence ao mesmo campo semântico de éleos (DANKER; BAUER, 2000). Eusplanchnoi possui o sentido mais específico de "generosos" ou "compassivos", como também ocorre na Oração de Manassés (MICHAELS, 1998). Introduz a longa citação de Sl 34,12-16. Os vv. 12 e 13 do Salmo 34, pela regra "áurea" da retórica de ter uma pergunta ocupando um lugar central dentro da estrutura (MEYNET, 2015), destacam-se como a parte central - e mais importante - deste salmo. Aliás, a citação do salmo 34 nesse ponto da carta tornase o cerne de toda a argumentação, uma vez que a paz, seja com todos (Rm 12,18) ou com os companheiros de fé $(1 \mathrm{Ts} 5,13 ; 2$ Cor 13,11$)$ era a preocupação maior na ética neotestamentária (MICHAELS, 1998).

1Pedro gosta de citar o Salmo 34 (33 Septuaginta) como texto básico para a ética cristã: já tinha citado este salmo em 1,19 e 2,3; mas existem várias outras passagens na carta que refletem alusões ou ecos ao salmo (1Pd 1,3.6.17.18; 2,6.16.17; 3,12) (CARSON, 2014). A citação de Sl 34,12-16 em 1Pd 3,10-12 ocorre sem nenhuma introdução formal, unindo-se ao argumento principal apenas pela partícula gar. Abandona-se a pergunta retórica do salmo 34, possivelmente porque utilizará sua própria pergunta retórica no v.13 para introduzir sua aplicação do salmo. Pedro ainda suaviza os imperativos na segunda pessoa do singular do salmo, mudando todos para a terceira pessoa do singular (MICHAELS, 1998). Essas mudanças poderiam ser não somente produto de uma editoração consciente, mas de uma possível Vorlage diferente da representada na Septuaginta (MICHAELS, 1998).

"Vida", com a qual o Salmo 34 denota uma vida longa e feliz sobre a terra, para Pedro é o mesmo que a "graça da vida" - a eterna salvação que consiste na esperança do crente. Amar a vida equivale a amar o Cristo ainda invisível, cuja vinda revelará essa salvação. Ver "bons dias" é ver o que não pode ser visto, a glória reservada aos cristãos naquela revelação. A linguagem do salmo é a linguagem deste mundo, mas para Pedro é metáfora para o mundo por vir (MICHAELS, 1998). No entanto, apenas 
alguns versículos antes, em 1Pd 2,24, a menção à vida mostra de fato a vida presente, com Pedro enfatizando que a vida escatológica já está presente por causa do renascimento alcançado pela ressurreição de Cristo (CARSON, 2014).

1Pedro, apesar da extensa citação, omitiu o resto do S1 34,17 (Septuaginta): "para destruir a memória deles da terra". Ele assim o faz, não puramente por estar se dirigindo a leitores cristãos, mas por relutar em detalhar o destino final dos ímpios, algo persistente em toda a epístola (1Pd 3,16.17; 4,5.18; e especialmente 5,5) (MICHAELS, 1998).

\section{Conclusão}

Viver os desafios de se cuidar da vida em tempos chamados "normais" já não é tarefa fácil. Em tempos de pandemia, como este do COVID-19, pior ainda, pois as situações de desafios se agigantam. Mesmo que tenhamos um otimismo de vontade e desejo de que tudo isso passe logo, o pessimismo de inteligência pede que desconfiemos; ainda que tenhamos boas intuições, a inteligência pede que desconfiemos; neste sentido a tradição popular nos ensina que "todo cuidado é pouco" e é preciso que estejamos alertas e atentos.

Em todos os momentos e situações a grande luz que nos é oferecida para cuidar da vida a temos nos critérios e no modelo da prática do Cristo compassivo e misericordioso, ou seja, cuidar como ele cuidou, tendo as mesmas atitudes que ele teve diante dos mais fragilizados. Se o tema da vida ganha realce com a pandemia, o da misericórdia torna-se urgente em situações já prevalecentes antes da COVID-19: intolerância, xenofobia, ódio manifesto a migrantes etc. Provavelmente a pandemia deu oportunidade para meditar sobre a misericórdia como meio de vida, a "melhorar nossos caminhos", seria necessário um vírus para tal meditação?

A vasta tradição bíblica, AT e NT, está repleta de gestos de Deus em favor da vida, desde a criação até a ressureição. Deus sempre esteve presente na vida de seu povo e igualmente de cada um de nós hoje. A pandemia tem ceifado vidas, aberto feridas e deixado lutos por todas as partes. Exige e exigirá cuidados maiores de cada um de nós. A prática de Cristo deverá ser o grande norte no retorno. Fomos jogados no futuro, sem direito a perceber o que exatamente estava a acontecer. A Mudança de Época realmente chegou e trouxe um novo tempo em todos os níveis. O grande desafio será sempre defender a vida diante de todas as ameaças e doenças possíveis: físicas, mentais, psicológicas e religiosas.

Todo tempo de Deus é e será sempre um laboratório que nos coloca na escuta da construção e ressignificação do futuro das relações humanas: consigo mesmo, com os outros e com o Outro por excelência, ou seja, com o Transcendente. Somos chamados a ser arquipélagos e não ilhas, a construir pontes e não muros, a defender a vida em todos os ambientes e situações. E as Sagradas Escrituras têm os grandes nortes e paradigmas para tanto.

Poder percorrer os vários corpora do NT (Sinopticum, Joannicum, Paulinum e Catholicum) e poder ver o agir de Cristo em defesa da vida, seguindo a grande tradição do AT, é iluminador e comprometedor ao mesmo tempo. O tema vida perpassa toda as Sagradas Escrituras, desde o Gênesis (AT) até o Apocalipse (NT), com intervenções de grande e misericordioso amor por parte de Deus em favor de seu povo. É óbvio que o ponto culminante da ação misericordiosa de Deus se dá na Cruz e no Ressuscitado de 
seu Filho e Senhor nosso, Jesus Cristo. Aqui no mysterium paschale nos é revelada a profundidade do amor misericordioso de Deus Pai em defesa da vida de todos nós, seus filhos e filhas.

Enfim, neste artigo podemos percorrer os vários corpora do NT, buscando ver como Deus defende a vida e como a Igreja Nascente foi percebendo e registrando isso a partir de suas várias correntes, como temos em cada livro, em cada corpus e em todos os corpora do NT. Os termos usados nos revelam a grande e plural possibilidade que temos em defender a vida, desde o cotidiano e o simples até as situações mais complicadas e desafiadoras que enfrentamos nos hodiernos desafios da pandemia do coronavírus: éleos (misericórdia), eleéō (agir com misericórdia), eleếmōn (misericordioso), eleèmosýne (prática da misericórdia, dar esmolas), splanchnizomai (movido por compaixão), agapē (amor), agapā̄ (amar), bios (vida), zōe (vida), indicando formas diferentes de se defender a vida dos mais fragilizados, que é diferente e complementar ao mesmo tempo.

\section{Referências Bibliográficas}

BAUCKHAM, Richard. J. 2Peter, Jude. Dallas: Word, Incorporated, 1998.

BUCHSEL, Friedrich. $\delta i ́ \delta \omega \mu \imath \chi \tau \lambda . ~ I n$ : KITTEL, Gerhard; BROMILEY, Geoffrey W.; FRIE-

DRICH, Gerhard (Orgs.). Grande Lessico del Nuovo Testamento. Brescia: Paideia, 1966. v. 2, p. 1171-1190.

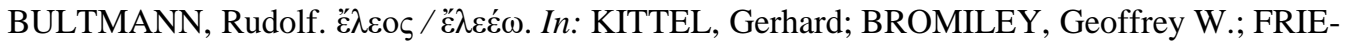
DRICH, Gerhard (Orgs.), Grande Lessico del Nuovo Testamento. Brescia: Paideia. v. 3, p. 399424.

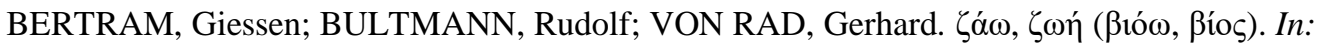
KITTEL, Gerhard; BROMILEY, Geoffrey W.; FRIEDRICH, Gerhard (Orgs.). Theological Dictionary of the New Testament. Grand Rapids, MI: Eerdmans. 1964. v. 2, p. 832-875.

CARSON, Donald A. 1Pedro. In: BEALE, Gregory K.; CARSON, Donald A. (Orgs.). Comentário do Uso do Antigo no Novo Testamento. São Paulo: Vida Nova, 2014. p. 1243-1280.

CLEMENTE ROMANO. Segunda Carta a los Corintios. In: PADRES Apostólicos, Texto Bilíngue Completo. Madrid: BAC, 1950. p. 355-372.

DANKER, Frederick W.; BAUER, Walter. A Greek-English Lexicon of the New Testament and Other Early Christian Literature. 3rd. ed. Chicago: University of Chicago Press, 2000.

DIDAQUÉ. La Doctrina de los Doce Apóstoles. In: PADRES Apostólicos, Texto Bilíngue Completo. Madrid: BAC, 1950. p. 27-94.

DILMANN, Rainer; MORA PAZ, César A. Comentario al Evangelio de Lucas. Madrid: Verbo Divino, 2016.

FITZMYER, Joseph A. El Evangelio según Lucas, II, Traducción y Comentario, Capítulos 18,21. Madrid: Cristiandad, 1987a.

., El Evangelio según Lucas, III, Traducción y Comentario, Capítulos 8,22-18,14. Madrid: Cristiandad, 1987b.

FRANCISCO. Carta Apostólica sob forma de Motu Proprio Misericordiae Vultus São Paulo: Paulinas, 2015. 
Carta Encíclica Laudato Si’. São Paulo: Paulinas, 2015.

Exortação Apostólica Pós Sinodal Evangelii Gaudium. São Paulo: Paulinas, 2013.

GONZAGA, Waldecir. Um Cristo compassivo e misericordioso (Lc 15,11-32). In: FERNANDES, Leonardo Agostini (Org.). Traços da Misericórdia de Deus segundo Lucas. Santo André: Academia Cristã; Rio de Janeiro: PUC-Rio, 2016. p. 92-112.

GRASSO, Santi. Il Vangelo di Luca. Roma: Città Nuona, 2019.

JOAO PAULO II. Carta Apostólica sob forma de Motu Proprio Misericordia Dei. São Paulo: Paulinas, 2002.

Carta Encíclica Dives in Misericordia. São Paulo: Paulinas, 1998.

KASPER, Walter. A misericórdia. Condição fundamental do Evangelho e chave da vida cristã. São Paulo: Loyola, 2014.

KOESTER, Craig R. Hebrews: A New Translation with Introduction and Commentary. New Haven; London: Yale University Press, 2008.

KÖSTER, Helmut. $\sigma \pi \lambda \alpha \dot{\gamma} \chi v o v, \sigma \pi \lambda \alpha \gamma \chi v i \zeta \zeta o \mu \alpha \iota \chi \tau \lambda$. In: KITTEL, Gerhard; BROMILEY, Geoffrey W.; FRIEDRICH, Gerhard (Orgs.). Grande Lessico del Nuovo Testamento. Brescia: Paideia, 1979. v. 12 , p. $903-934$.

LIMA, Maria de Lourdes C.; BOUZON, Manuel. Hesed nos escritos de Oseias: significado e valor teológico. Elementos para a história e evolução de um conceito bíblico. 1990. Dissertação (Mestrado em Teologia) - Departamento de Teologia, Pontifícia Universidade Católica do Rio de Janeiro, Rio de Janeiro. 2v.

LINK, Hans-Georg; ZABATIERO, Júlio P. T. Vida. In: COENEN, Lothar; BROWN, Collin. Dicionário Internacional de Teologia do Novo Testamento. São Paulo: Vida Nova, 2000. v. 2, p. 2641-2652.

MAZZAROLO, Isidoro. A misericórdia exige proximidade a aproximação: uma e leitura da superação do puro e impuro em Lc 7,11-17; 10,29-37; 15,11-32. In: FERNANDES, Leonardo. A. (Org.). Traços da Misericórdia de Deus segundo Lucas. Santo André: Academia Cristã; Rio de Janeiro: PUC-Rio, 2016. p. 72-91.

MEYNET, Roland. Il Vangelo secondo Luca. Roma: Dehoniane, 1994.

MEYNET, Roland. Les huit psaumes acrostiches alphabétiques. Roma: G\&B Press, 2015.

MICHAELS, J. Ramsey. 1 Peter. Dallas: Word, Incorporated, 1998.

NESTLE-ALAND. Novum Testamentum Graece, 28th. ed. Stuttgart: Deutsche Bibelgesellschaft, 2012.

PÉREZ MILLOS, Samuel. Lucas. Barcelona: CLIE, 2017.

POLICARPO DE ESMIRNA. Segunda Carta a los Filipenses. In: PADRES Apostólicos, Texto Bilíngue Completo. Madrid: BAC, 1950. p. 631-671.

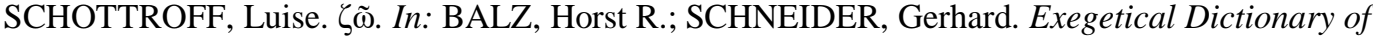
the New Testament. Grand Rapids, Mich.: Eerdmans, 1991. v. 2. p. 105-109. 


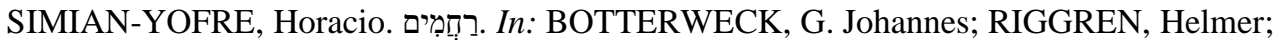
FABRY, Heinz-Josef. Grande Lessico del Antico Testamento. Brescia: Paideia, 2008. v.8, p. 351370.

ZOBEL, Hans-Jürgen. Tơֶ . In: BOTTERWECK, G. Johannes; RIGGREN, Helmer; FABRY, Heinz-Josef. Grande Lessico del Antico Testamento. Brescia: Paideia, 2003. v. 3, p. 57-83. 